\title{
Exploration of pension funding in case of exact vesting *
}

\author{
Cecil J. NESBITT \\ Actuarial Education and Research Fund, c/o University of \\ Michigan, Department of Mathematics, Ann Arbor, MI 48109, \\ USA
}

Received 12 March 1982

A pension plan is said to be exactly vested if it provides, in addition to the benefit available upon retirement, a benefit, upon termination for any cause prior to retirement, which is exactly equivalent to the actuaria! accrued liability for the terminating participant.

The concept of exact vesting has simple application in defined contribution plans such as those of the Teachers Insurance and Annuity Association. It is also feasible to develop the exact vesting concept for a defined benefit plan which uses an individual type of actuarial cost method. An exactly vested plan would have more individual equity than is available under customary vesting and early retirement provisions of defined benefit plans.

In this paper, theory is developed for an exacily vested model plan in parallel to the theory for a pure pension radel plan discussed in previous papers on pension funding dynamics.

Keywords: Exact vesting, Vesting benefit, Pure pension plan. Pension funding dynamics.

\section{Introduction}

In a recently published paper and in a forthcoming paper, Newton Bowers, James Hickman, and I $(1976,1979)$ discussed the dynamics of pension funding in terms of a model plan. A major simplification was to consider only retirement benefits, in other words, we discussed a pure pension plan. Vested benefits upon termination before retirement, and benefits for early retirement were not considered, although in practice a well designed pension plan will provide for both. Classical terminology such as 'normal cost' and 'accrued liability' was used in Bowers, Hickman and Nesbitt

\footnotetext{
* Published with kind permission of ARCH.
}

(1976) but here an attempt will be made to utilize terminology proposed in the IPAA Group Report (1978).

In life insurance, a policyholder who terminates the insurance contract before its completion receives the approximate equivalent of the asset share that has been funded under the contract. In a pension plan, a participant who terminates before normal retirement age receives a benefit defined in terms of service and salary to date, and the value of such benefit may well be different from the supplement actuarial value (accrued liability or reserve) that has been established by the actuarial cost method utilized for the plan. This difference between the basis of non-forfeiture benefits in life insurance and the basis of vested and early retirement benefits in pension plans has gnawed at my mind for years, but I have not noted any references in the literature to it (see, for example, Trowbridge (1972), Winklevoss and Shapiro (1972)). For this reason, I have turned to the model plan in the papers of Bowers, Hickman and Nesbitt $(1976,1979)$ to see what insight it can give regarding the matter. In doing so, I have modified the model plan by assuming that in addition to the retirement benefit available at age $r$ there is available, on termination for any reason prior to age $r, a$ benefit (lump sum, deferred annuity or combination) equivalent to the supplemental actuarial value (reserve) in regard to the terminating participant. A plan with this feature will be said to be exactly vested. Here the benefit for early retirement is provided through the vesting mechanism. It would appear that for such a plan it would be necessary to use an actuarial cost method which defines supplemental actuarial values for each participant.

The concept of exact vesting has simple application in defined contribution plans such as those of the Teachers Insurance and Annuity Association (TIAA). Note that exact vesting, as defined, implies immediate vesting, as is the case with TIAA. It now appears feasible to develop the exact vesting concept for defined benefit plans 
which utilize an individual type of actuarial cost method. An exactly vested plan would have more individual equity than is available under the usual vesting and early retirement provisions of defined benefit plans. As the supplemental actuarial value would usually take account of projected salary, the vested benefit would in that sense be related to projected rather than current salary and for that reason a more adequate benefit might emerge.

The calculation of the annual actuarial value (normal cost) and the supplemental actuarial value (accrued liability) will be simplified by requiring only discount under interest of the purchased projected benefit from age $r$ if a Cooper-Hickman type of general accrued benefit actuarial cost method Cooper and Hickman (1967) is used (as is the case for the mathematical model in Bowers, Hickman and Nesbitt (1976, 1979)). This should be clear intuitively since in essence the reserve for the participant is available in case of termination before age $r$, and no reserve change in occasioned by the participant's termination. In contrast, in a pure pension plan the purchased projected retirement benefits are discounted in regard to interest and all causes of termination before age $r$, and reserve is released upon a termination. In practice, upon withdrawal or early retirement there is some change in the reserve requirement under the usual provisions for defined benefit plans.

On the other hand, an exactly vested defined benefit plan is a more complex instrument than a pure pension plan. In what follows, theory will be developed for an exactly vested model plan and contrasted with the theory for the pure pension model plan discussed in Bowers, Hickman and ivesbitt $(1976,1979)$.

\section{The exactly vested model plan}

A summary of the model plan is as follows (cf. Bowers, Hickman and Nesbitt (1976), p. 185). All new entrants join the plan at age $a$ and all normal retirements occur at age $r$. On termination before age $r$, an exactly vested benefit equivalent to the supplemental actuarial value for the terminating participant is available, and on retirement at age $r$, the normal benefit begins. For both active and retired participants, survivorship is deterministic and is in accordance with the function $l_{x}$ which does not depend on the time variable $t$. At time zero, the density of new retirants at age $r$ is $l_{r}$, and thereafter this density increases by a factor $g_{1}(t)$. This establishes a generation pattern of growth for participants. It is assumed that $g_{1}(t)>0$ for $t>0$, which implies a positive density $g_{1}(t+r-x) l_{x}$ of members aged $x, a \leqslant x \leqslant r$. Salary rates at time zero are represented by the function $s(x)$, for a member aged $x, a \leqslant x \leqslant r$. Thereafter, salary rates increase by a factor $g_{2}(t)$ which establishes a yearof-experience pattern of growth of salaries. The rate of initial annual pension payment, commericing at age $r$, is a fixed positive fraction $b$ of the final salary rate. Pension payment rates increase during retirement by a factor $\beta(x)$.

For $a \leqslant x \leqslant r$, the density of new pensions to be incurred at time $t+r-x$, in respect to survivors of members aged $x$ at time $t$, is given by the function

$$
\begin{aligned}
h(t+r-x)= & g_{1}(t+r-x) g_{2}(t+r-x) \\
& \times l_{r} s(r) b .
\end{aligned}
$$

For $x=r, h(t)$ is the density of new pensions incurred at time $t$ for the $g_{1}(t) l_{r}$ members attaining age $r$ at time $t$. Further,

$h(t+r-x)\left(l_{x} / l_{r}\right)$

is the potential pension density in regard to members aged $x$ at time $t$ (before discounting in regard to survivorship from age $x$ to age $r$. This corresponds in practice to the potential pensions for members aged $x$ on a valuation date).

In order to discuss the exactly vested model plan, we shall first recall a number of functions used to describe the pure pension model plan of Bowers, Hickman and Nesbitt (1976, 1979).

\section{Functions for the pure pension model plan}

In Bowers, Hickman and Nesbitt (1976), certain functions relating to a unit of pension were defined. These definitions in regard to a unit of initial pension from age $r$ for a participant aged $x$ are as follows: ments:

$A(x)$, the actuarial present value of future pay-

$A(x)=\mathrm{e}^{-\delta(r-x)}\left(l_{r} / l_{x}\right) \bar{a}_{r}^{\beta}=\left(D_{r} / D_{x}\right) \bar{a}_{r}^{\beta}$

where $\delta$ denotes the assumed force of interest, and the superscript $\beta$ on the annuity value indicates that the annuity payments are adjusted by the function $\beta(y), y \geqslant r$. 
$P(x)$, the actuarial annual (normal cost) rate:

$$
\begin{aligned}
P(x) & =\mathrm{e}^{-\delta(r-x)}\left(l_{r} / l_{x}\right) \bar{a}_{r}^{\beta} m(x) \\
& =A(x) m(x),
\end{aligned}
$$

where $m(x)$ is the pension purchase density function (cf. Cooper and Hickman (1967)).

$V(x)$, the supplementai actuarial value (accrued liability):

$$
\begin{aligned}
V(x) & =\mathrm{e}^{-\delta(r-x)}\left(l_{r} / l_{x}\right) \bar{a}_{r}^{\beta} M(x) \\
& =A(x) M(x),
\end{aligned}
$$

where $M(x)=\int_{a}^{x} m(y) \mathrm{d} y$.

$(P a)(x)$, the actuarial present value of future normal costs:

$(P a)(x)=A(x)-V(x)$.

In Bowers, Hickman and Nesbitt (1979), corresponding functions in regard to the potential benefits for the group of active members were defined for the case of the pure pension model plan, namely:

$(a A)(t)$, the actuarial present value at time $t$ for the then active members:

$$
\begin{aligned}
(a A)(t) & =\int_{a}^{r} h(t+r-x) \mathrm{e}^{-\delta(r-x)} \bar{a}_{r}^{\beta} \mathrm{d} x \\
& =\int_{a}^{r} h(t+r-x)\left(l_{x} / l_{r}\right) A(x) \mathrm{d} x .
\end{aligned}
$$

$\boldsymbol{P}(t)$, the actuarial annual (normal cost) rate for the plan at time $t$ :

$P(t)=\int_{a}^{r} h(t+r-x)\left(l_{x} / l_{r}\right) P(x) \mathrm{d} x$.

$(a V)(t)$, the supplemental actuarial value (accrued liability) of the plan at time $t$ for the then active members:

$$
\begin{aligned}
(a V)(t)= & \int_{a}^{r} h(t+r-x)\left(l_{x} / l_{r}\right) V(x) \mathrm{d} x \\
(\boldsymbol{P a})(t)= & \int_{a}^{r} h(t+r-x)\left(l_{x} / l_{r}\right)(P a)(x) \mathrm{d} t \\
= & \int_{a}^{r} h(t+r-x)\left(l_{x} / l_{r}\right) \\
& \times[A(x)-V(x)] \mathrm{d} x \\
= & (a A)(x)-(a V)(x) .
\end{aligned}
$$

There will also be need of ${ }^{\mathrm{T}} \boldsymbol{P}(t)$, the annual rate of terminal funding normal cost for the plan at time $t:$

$$
{ }^{\mathrm{T}} \boldsymbol{P}(t)=h(t) \bar{a}_{r}^{\beta} .
$$

In Bowers, Hickman and Nesbitt (1979), formulas (7)-(10) were expressed in terms of ${ }^{\mathrm{T}} \boldsymbol{P}(t)$ but for our present purposes it seems better to use the equivalent expressions with $h(t)$ as explicit factor.

As a next step, we define for the exactly vested model plan, unit functions corresponding to those in formulas (3)-(6).

\section{Unit functions for the exactly vested plan}

For our purposes hereon, we need some conventions about notation. These are:

1. When a function for the exactly vested plan is not split into components for pure pension and for exact vesting, notations as in the preceding section will be used with a tilde on top, for example, $\tilde{P}(x)$ and $\tilde{P}(t)$.

2. When a function for the exactly vested plan is split into a component for pure pension and a component for exact vesting, the pure pension component will be denoted as in the preceding section, and the exact vesting component will be denoted by appending the letter $w$ in the function symbol, thus

$\tilde{P}(x)=P(x)+(P w)(x)$.

In such cases the tilde is omitted from the symbol for the vesting component since the $w$ indicates that one is dealing with a vested plan.

One might ask why not use a superscript $(w)$ to denote the second component. That would work fine for the functions $(A w)(x)$ and $(A w)(x)$ but could be misleading for the other functions as we shall see. The notation is a mild experiment with linear symbols and might have employed $v$ (for vesting) as the appended letter but this confuses with the compound interest $v$. Instead, we shall use $w$ which is indicative of withdrawal.

We are now ready to discuss the unit functions for the exactly vested model plan, that is, functions in regard to a unit of initial pension from age $r$ for a participant aged $x$ with the condition that there is exact vesting in case of termination before age $r$. Here it is convenient to treat together

$\tilde{P}(x)$, the actuarial annual (normal cost) rate,

$\tilde{V}(x)$, the supplemental actuarial value.

A defining equation for $\tilde{V}(x)$ is

$$
\begin{aligned}
\frac{\mathrm{d} \tilde{V}(x)}{\mathrm{d} x} & =\tilde{P}(x)+\left(\mu_{x}+\delta\right) \tilde{V}(x)-\mu_{x} \tilde{V}(x) \\
& =\tilde{P}(x)+\delta \tilde{V}(x),
\end{aligned}
$$


which indicates that this is a savings fund operation. In fact, using the conditions $\tilde{V}(a)=0, \tilde{V}(r)$ $=\bar{a}_{r}^{\beta}$, one may solve equation (12) for $\tilde{V}(x)$ in the equivalent forms

$$
\begin{aligned}
& \tilde{V}(x)=\int_{a}^{x} \mathrm{e}^{\delta(x-y)} \tilde{P}(y) \mathrm{d} y, \\
& \tilde{V}(x)=\mathrm{e}^{-\delta(r-x)} \bar{a}_{r}^{\beta}-\int_{x}^{r} \mathrm{e}^{-\delta(y-x)} \tilde{P}(y) \mathrm{d} y .
\end{aligned}
$$

Further, a consistent way to obtain exact vesting is to set

$\tilde{P}(x)=P(x)+\tilde{P}(x)\left(1-l_{r} / l_{x}\right)$.

Thereby, $\tilde{P}(\mathrm{x})$ provides the pure pension normal cost and also for the return with accumulated interest of $\tilde{P}(x)$ in case of termination before age $r$. We denote the second component by $\left(P_{w^{\prime}}\right)(x)$ and see that

$$
(P w)(x)=\tilde{P}(x)\left(1-l_{r} / l_{x}\right)
$$

does not provide for the vesting of prior or future normal costs other than the immediate $\tilde{P}(x) \mathrm{d} x$. That is the sense in which it would be misleading to label $(P w) x$ as $P^{(w)}(x)$. From formulas (15) and (4), we have immediately

$\tilde{P}(x)=P(x)\left(l_{x} / l_{r}\right)=\mathrm{e}^{-\delta(r-x)} \bar{a}_{r}^{\beta} m(x)$.

Here the discounting factor from age $r$ to age $x$ is under interest only, unlike the situation for the pure pension case. One should note how $\tilde{P}(x) / P(x)=l_{x} / l_{r}$ differs from formula (3) of Trowbridge (1972).

Alternative forms for $\tilde{V}(x)$ now are

$$
\begin{aligned}
& \tilde{V}(x)=\mathrm{e}^{-\delta(r-x)} \bar{a}_{r}^{\beta} M(x)=V(x)\left(I_{x} / I_{r}\right), \\
& \tilde{V}(x)=V(x)+\tilde{V}(x)\left(1-I_{r} / I_{x}\right), \\
& \tilde{V}(x)=V(x)+(V w)(x) .
\end{aligned}
$$

$\tilde{A}(x)$, the actuarial present value of future benefits including those for both vesting and for retirement:

$\tilde{A}(x)=A(x)+(A w)(x)$,

where

$(A w)(x)=\int_{x}^{r} \mathrm{e}^{-\delta(y-x)}\left(l_{y} / l_{x}\right) \mu_{y} \tilde{V}(y) \mathrm{d} y$.

Formulas (21) and (22) are more or less evident but, if one prefers, they can be obtained by starting with the defining equation

$$
\frac{\mathrm{d} \tilde{A}(x)}{\mathrm{d} x}=\left(\mu_{x}+\delta\right) \tilde{A}(x)-\mu_{x} \tilde{V}(x)
$$

with the curdilion $\tilde{A}(r)=\bar{a}_{r}^{\beta}$, and solving for $\tilde{A}(x)$. Here it would not be misleading to denote $(A w)(x)$ by $A^{(n)}(x)$ since formula (22) indicates that the full vested benefit in future years is valued and not merely the portion from $\tilde{P}(x)$ or $\tilde{V}(x)$ at age $x$.

$(\tilde{P} a)(x)$, the actuarial present value of future normal costs:

$(\tilde{P} a)(x)=\tilde{A}(x)-\tilde{V}(x)$.

Applying formulas (21), (20), and (6) one gets

$(\tilde{P} a)(x)=(P a)(x)+(A w)(x)-\left(V_{w}\right)(x)$.

Thus $(\tilde{P} a)(x)$ equals the actuarial present value of future normal costs for the pure pension benefit plus the difference between the actuarial present value of future vesting benefits less the value of the vesting benefit arising from $\tilde{V}(x)$. Consistent with previous notation, this difference will be denoted by $\left(\mathrm{Pa}: w^{\prime}\right)(x)$, that is

$(P a: w)(x)=(A w)(x)-(V w)(x)$.

\section{Active group functions for the exactly vested plan}

Proceeding as for formulas (7)-(10), we now get corresponding active group functions for the exactly vested plan:

$\tilde{\boldsymbol{P}}(t)$, the actuarial annual (normal cost) rate for the plan at time $t$ :

$\tilde{\boldsymbol{P}}(t)=\int_{a}^{r} h(t+r-x)\left(l_{v} / l_{r}\right) \tilde{P}(x) \mathrm{d} x$.

Formula (27) can be re-expressed in various ways such as

$\tilde{\boldsymbol{P}}(t)=\boldsymbol{P}(t)+\left(\boldsymbol{P} w^{v}\right)(t)$,

where

$\left(P_{w}\right)(t)=\int_{a}^{r} h(t+r-x)\left(l_{x} / l_{r}\right)\left(P_{w}\right)(x) \mathrm{d} x$

or as

$\tilde{\boldsymbol{P}}(t)=\int_{a}^{r} h(t+r-x)\left(I_{x} / l_{r}\right) \mathrm{e}^{-\delta(r-x} \bar{a}_{r}^{\beta \beta} m(x) \mathrm{d} x$.

$(a \bar{V})(t)$, the supplemental actuarial value of the plan lor the then active members:

$$
\begin{aligned}
(a \tilde{V})(t) & =\int_{a}^{r} h(t+r-x)\left(l_{v} / l_{r}\right) \tilde{V}(x) \mathrm{d} x \\
& =(a V)(t)+\left(V_{w^{\prime}}\right)(t)
\end{aligned}
$$




$$
\begin{aligned}
= & \int_{a}^{r} h(t+r-x)\left(l_{x} / l_{r}\right) \\
& \times \mathrm{e}^{-\delta(r-x)} \tilde{a}_{r}^{\beta} M(x) \mathrm{d} x .
\end{aligned}
$$

$(a \tilde{A})(t)$, the actuarial present value at time $t$ for the then active members:

$$
\begin{aligned}
(a \tilde{A})(t)= & \int_{a}^{r} h(t+r-x)\left(l_{x} / I_{r}\right) \ddot{A}(x) \mathrm{d} x \\
= & \int_{a}^{r} h(t+r-x)\left(l_{x} / l_{r}\right) \\
& \times[A(x)+(A w)(x)] \mathrm{d} x \\
= & (a A)(t)+\left(a A w^{\prime}\right)(t) .
\end{aligned}
$$

$(\tilde{\boldsymbol{P}} \boldsymbol{a})(t)$, the actuarial present value at time $t$ of future normal costs for the then active members:

$$
\begin{aligned}
(\tilde{\boldsymbol{P}} \boldsymbol{a})(t) & =\int_{a}^{r} h(t+r-x)\left(l_{x} / l_{r}\right)(\tilde{P} a)(x) \mathrm{d} x \\
& =(\boldsymbol{P a})(t)+\left(\boldsymbol{P} \boldsymbol{u}^{\prime}\right)(t) \\
& =(\boldsymbol{a} \tilde{A})(t)-(\boldsymbol{a} \tilde{V})(t) .
\end{aligned}
$$

\section{General relations}

One can start with either formula (30). or the last of formulas (3l), to obtain the relation

$$
\begin{aligned}
\tilde{P}(t)+\delta(a \tilde{V})(t)= & { }^{\mathrm{T}} \boldsymbol{P}(t)+(B w)(t) \\
& +\frac{\mathrm{d}}{\mathrm{d} t}(a \tilde{V})(t) .
\end{aligned}
$$

where

$$
(B w)(t)=\int_{a}^{r} h(t+r-x)\left(I_{v} / I_{r}\right) \mu_{v} \tilde{V}(x) \mathrm{d} x
$$

is the annual outgo rate at time $t$ for vested benefits. Formula (34) is an income allocation statement which states that the actuarial annuis: value plus interest on the supplemental actuartat value for active members is allocated to the terninal funding cost of those retiring. to the outgo for vested benefits. and to the change in the stppicmental actuarial value for active members. The corresponding income allocation equation for the pure pension plan is

$P(t)+\delta(a V)(t)=T P(t)+\frac{d}{d t}(a V)(t)$

Subtraction of formula ( 36 ) from formula (35) and use of the relations in the preceding section yielu

$\left(P_{w^{\prime}}\right)(t)+\delta\left(V_{w^{\prime}}\right)(t)=\left(B_{w^{*}}\right)(t)+\frac{\mathrm{d}}{\mathrm{d} t}\left(V_{w^{\prime}}\right)(t)$.
Formula (37) allocates the actuariai dnnual value for vesting plus the interest income on the supplemental actuarial value for vested benefits to the current outgo for vested benefits and the change in the suiplementa! dituarial value for vested benefits.

\section{The experantial growth casc}

More explicit formulas are obtainable in the exponential growth case where $g_{4}(t)=$ "' (population growthi, $g_{2}(t)=e^{\prime \prime}$ (salary grow $(h)$, and $h(t)=g_{1}(t) g_{2}(t) l_{r} s(r) b=\mathrm{e}^{\tau t} l_{r} s(r) b$ with $\tau=\alpha+\gamma$ being the total growith rate. In this case, an active group function such as $\tilde{P}(t)$ is of the form e $\tilde{\boldsymbol{P}}(0)$, and $\mathrm{d} \tilde{\boldsymbol{P}}(t) / \mathrm{d} t=\tau \tilde{\boldsymbol{P}}(t)$, that is. each of the acin's group functions grows at the total grow ih rate $\rightarrow$. Moreover, in the exponential growth case, it is $\mathrm{m}$ in Bowers, llickman and Nesbitt (1979). tha: "or the pure pension model plan there is an average age $\hat{x}$ for payment of the unnual actuarial value assoriated with the uciuarial cost method deîned by $m(x)$ and the difference $\theta=\delta-\tau$ between the iriterest and growth rates. This leads to the concept of a past funding term of

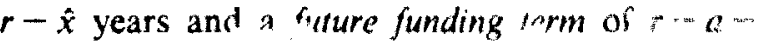
$(r-\hat{x})=?$ a $j$ ars such that:

$\boldsymbol{P}(t)={ }^{\mathrm{T}} \boldsymbol{P}(t) \boldsymbol{v}^{r-*}$.

w. ${ }^{-e} v=\mathrm{e}^{-\theta}$. and all subsequnt interest functions unless oth-rwise forre? $=\delta-\tau$.

$$
\begin{aligned}
& (a V)(1)={ }^{\mathrm{T}} \boldsymbol{P}(t) \bar{a}_{r \cdots \cdot k} \cdot \\
& (a A)(t)={ }^{\top} P(t) \bar{a}_{r-a t} . \\
& (t a)(t)=(a A)(t)-(a V)(t) \text {. } \\
& ={ }^{\mathrm{T}} \boldsymbol{P}(t) v^{r-\hat{x}} \overline{a_{\hat{x}-a l}}, \\
& =\boldsymbol{P}(l) \bar{a}_{i-a} \text {. }
\end{aligned}
$$

In effect.

$$
P(t)=\mathrm{e}^{\text {st }} \text { is } \mathrm{e}^{\text {tr } r \text { ist } P(t)}
$$

remains in the fund until $r-\hat{x}$ years elapse at which time it is sufficient to provide

$\mathrm{e}^{\tau(r-\hat{x}) T} \boldsymbol{P}(t)={ }^{\top} \boldsymbol{P}(t \cdots-\hat{x})$.

the then terminal fund $w_{c}$ cost. Further, $\{a V)(t)$. on hand at time $t$, suffices to provide the terminal funding costs for the next $r-\hat{x}$ years, $(a A)(t)$ is 
equivalent to the terminal funding costs for the total funding term of $r-a$ years, and $(P a)(t)$ provides for the terminal funding costs after the past funding term of $r-\hat{x}$ years has elapsed.

For the exactly vested plan, the exponential growth case can be analyzed in various ways. One such analysis leads to

$\tilde{\boldsymbol{P}}(t)={ }^{\mathrm{T}} \boldsymbol{P}(t) v^{r-\hat{x}}+(\boldsymbol{P} w)(t)$,

that is, $\tilde{\boldsymbol{P}}(t)$ provides the terminal funding cost $r-\hat{x}$ years later. and also the vested benefits arising from $\hat{\boldsymbol{P}}(t)$.

Now the income allocation equation (34) becomes

$\tilde{P}(t)+\delta(a \tilde{V})(t)={ }^{\mathrm{T}} \boldsymbol{P}(t)+\left(B_{w}\right)(t)+\tau(a \tilde{V})(t)$

which yields

$$
\begin{aligned}
& (a \tilde{V})(t)=\left[{ }^{\mathrm{T}} \boldsymbol{P}(t)-\tilde{\boldsymbol{P}}(t)+(B w)(t)\right] / \theta \\
& \quad=\left[{ }^{\mathrm{T}} \boldsymbol{P}(t)-\boldsymbol{P}(t)-(\boldsymbol{P} w)(t)+(B w)(t)\right] / \theta \\
& ={ }^{\mathrm{T}} \boldsymbol{P}(t) \bar{a}_{r-\bar{x} \mid}+[(B w)(t)-(\boldsymbol{P} w)(t)] \bar{a}_{\bar{x} \mid} .
\end{aligned}
$$

Here $(a \tilde{V})(t)$ is equivalent to the terminal funding costs for $r-\hat{x}$ years plus the perpetuity of all future vested benefits (including those for future new entrants) less the perpetuity of vested benefits arising from all future normal costs (including those for future new entrants).

$$
\begin{aligned}
& (a \tilde{A})(t)=(a A)(t)+(a A w)(t) \\
& \quad={ }^{\top} P(t) \bar{a}_{r-a \mid}+\left[(B w)(t){ }^{-1}\left(\boldsymbol{P}_{w}\right)(t)\right] \bar{a}_{\bar{x} \mid},
\end{aligned}
$$

where

$$
'(P w)(t)=h(t+r-a)\left(l_{a} / l_{r}\right)(A w)(a)
$$

is the annual rate at which actuarial present value of vested benefits is being assumed for new entrants at time $t$ or, as the notation indicates, the actuarial annual (normal cost) rate for vested benefits under the initial funding cost method. Formula (46) can be verified by noting that the perpetuity of all future vested benefits less the perpetuity of vested benefits for future new entrants is equivalent to the vested benefits for the current active members.

Finally,

$$
\begin{aligned}
(\tilde{P} a)(t)= & (a \tilde{A})(t)-(a \bar{V})(t) \\
= & { }^{\top} P(t) v^{r-\hat{x}} \bar{a}_{\hat{x}-a \mid} \\
& +\left[\left(\boldsymbol{P}_{w}\right)(t)-{ }^{\prime}(P w) t\right] \bar{a}_{\bar{x} \mid}
\end{aligned}
$$

This has the somewhat mysterious interpretation that the future actuarial annual values (normal costs) for the present active members are equivalent to terminal funding costs over the future funding term and the difference between a perpetuity of vested benefits arising from future normal costs and a perpetuity of vested benefits for future new entrants.

\section{Conclusion}

The concept of exact vesting is already in operation for some defined contribution plans and may, in modified form, also be in effect for some defined benefit plans, or for the hybrid 'target plans' (Anderson (1976), p. 317). Application of the concept could greatly strengthen individual equity under defined benefit plans and would provide more adequate vested benefits in an inflationary period, as the benefits would take account of projected salary at retirement and not simply the current salary. Such improved vesting would be at the expense of lower pensions if overall costs are not to increase. From one point of view the theory of such plans is simple as they operate as directed savings plans. However, comparison with a pure pension plan can lead to considerable analysis. Variations and refinements of the analysis presented here clearly exist. It remains to be seen whether the concept will gather substance in the pension field.

\section{References}

Anderson, A.W. (1976). Social security integration. Trans. Soc. Actuaries 28, 287-320.

Rowers, N.L.. Jr., Hickman, J.C., and Nesbill, C.J. (1976). Introduction to the dynamics of pension funding. Trans. Soc. Actunies 28, 177-203.

Bowers, N.L., Jr., Hickman. J.C.. and Nesbitt, C.J. (1979). The dynamics of pension funding: Contribution theory. Trans. Soc. Actuaries 31. 93-119.

Cooper, S.L. and Hickman. J.C. (1967). A family of accrued benefit actuarial cost methods. Trans. Soc. Actuaries 19. 53-59.

Interprofessional Pension Actuarial Advisory Group. Pension Terminology Final Report. January 20, 1978. Available from American Academy of Actuaries. $1835 \mathrm{~K}$ Street. N.W.. Suite S15, Washington, DC 20006. USA.

Trow uridge. C.L. (1972). Cost of vesting in private pension plans, Trans. Soc. Actuaries 24, 397-410.

Winklevoss. H.E. and Shapiro. A.F. (1972). Estimating the cost of vesting in pension plans, Trans. Soc. Acruaries 24. 373394. 